\title{
The Attraction Effect in Experience-based Decisions
}

\author{
LIAT HADAR, ${ }^{1 *}$ (iD SHAI DANZIGER ${ }^{2,3}$ and RALPH HERTWIG ${ }^{4}$ \\ ${ }^{1}$ Interdisciplinary Center (IDC) Herzliya, Herzliya, Israel \\ ${ }^{2}$ Coller School of Management, Tel Aviv University, Tel Aviv, Israel \\ ${ }^{3}$ University of Sydney Business School, Australia \\ ${ }^{4}$ Max Planck Institute for Human Development, Berlin, Germany
}

\begin{abstract}
Previous demonstrations of the attraction effect were limited to explicitly described attribute values (including numerically indexed attributes, such as gambles' outcomes and their likelihoods, or perceptual attributes, such as rectangles' height and width). However, in many real-life decisions, such as the choice of a preferred grocer, people decide based on their past experience with the options' attributes (e.g., the frequency and magnitude of product discounts over time). We examine whether the attraction effect extends from description-based to experience-based choice between gambles. Our results demonstrate that the attraction effect exists but is less prevalent in experience-based than in descriptionbased choice. This is because the dominance relationship, necessary for the attraction effect to occur, is more difficult to recognize in experience-based choice. Yet, when dominance is recognized, people may use it to guide difficult trade-off choices. We discuss practical implications. Copyright (C) 2018 John Wiley \& Sons, Ltd.
\end{abstract}

KEY WORDS attraction effect; asymmetric dominance; experience-based choice

Imagine moving to a new city and contemplating at which grocery store to shop. You shop at two nearby stores for several weeks and observe that store A offers rare but large discounts, whereas store B offers frequent but small discounts. Which store are you more likely to choose on your next shopping trip? Now imagine monitoring the frequency and the magnitude of discounts at three stores - the same two stores from the previous example, as well as store C, which has recently opened. Monitoring the performance of the stores for several more weeks, you realize that although store $\mathrm{C}$ offers small discounts, similar to store B, they are not as frequent as those offered by store B. Which store are you more likely to choose for your next shopping trip in this case?

An extant research on consumer choice suggests that the choice share of store $\mathrm{B}$ will be higher when store $\mathrm{C}$ is also considered than when it is not. According to the asymmetric dominance or attraction effect (Huber, Payne, \& Puto, 1982; Huber \& Puto, 1983; Simonson, 1989), adding an inferior option (a decoy) to a two-option choice set characterized by a difficult trade-off between two attributes will increase the choice share of the option that dominates the decoy. People appear to "solve" the difficult trade-off by choosing the dominating option (Amir \& Levav, 2008; Evangelidis \& Levav, 2013; Levav, Kivetz, \& Cho, 2010; Simonson, 1989; Simonson \& Nowlis, 2000; Simonson \& Tversky, 1992). Per the opening example, considering store $C$, in addition to stores $\mathrm{A}$ and $\mathrm{B}$, is expected to help consumers solve the difficult trade-off between discount frequency and magnitude by choosing store $\mathrm{B}$, which dominates store $\mathrm{C}$ in terms of discount frequency.

*Correspondence to: Liat Hadar, Arison School of Business, Interdisciplinary Center Herzliya (IDC), P.O. Box 167, Herzliya 46150, Israel. E-mail: lhadar@idc.ac.il
The attraction effect is one of the most well-known and researched choice phenomena. Over the past 30 years, it has been replicated across numerous research domains, such as consumer behavior (for a review, see Frederick, Lee, \& Baskin, 2014), memory (Maylor \& Roberts, 2007), law (Kelman, Rottenstreich, \& Tversky, 1996), policy (Herne, 1997), personnel assessment (Slaughter, Sinar, \& Highhouse, 1999), and leadership (Moran \& Meyer, 2006), using various types of choice problems, in choice sets characterized by numerically indexed attributes (Frederick et al., 2014; Huber \& Puto, 1983; Huber et al., 1982; Simonson, 1989) and with perceptual attributes (Trueblood, 2012; Trueblood, Brown, Heathcote, \& Busemeyer, 2013; Trueblood \& Pettibone, 2017), with hypothetical and real consequences, and with various subject populations. The attraction effect was originally used to demonstrate a violation of the regularity axiom (according to which the probability of choosing an option cannot be increased by adding another option to the choice set; Luce, 1977). Nonetheless, it was soon recognized as an important choice-architecture tool by practitioners, because the composition of choice sets is readily manipulated (Frederick et al., 2014; Huber, Payne, \& Puto, 2014).

Despite extensive research, previous demonstrations of the attraction effect were limited to situations in which the choice options' attribute values were described to participants. For example, in the original demonstration of the attraction effect, participants were provided information regarding lotteries' winning amounts and chances of winning and restaurants' driving time and food quality (Huber et al., 1982). However, people do not always base their decisions on explicitly described options. Often times, decision makers need to experience attribute values (Barron \& Erev, 2003; Hertwig, 2012; Hertwig, Barron, Weber, \& Erev, 2004). For instance, when people choose a preferred grocer (as in the opening example), slot machine, or a route to work, they typically do not know in advance what discounts the 
available grocers offer, the distribution of payoffs offered by each slot machine, or how busy the relevant roads will be, nor do they know the likelihood of each of these events. Instead, they learn this information after sampling alternative grocers, slot machines, or routes.

Because people often make decisions based on their experience with product attributes rather than on descriptions thereof, it is important to examine the attraction effect in the context of experience-based decisions. In this paper, we are the first to examine whether the attraction effect exists in experience-based choice. ${ }^{1}$ We contend the attraction effect is less prevalent in decisions based on experience than in decisions based on descriptions. This is because recognizing the dominance relation is necessary for the attraction effect to occur and because recognizing the dominance relationship is more difficult when it must be inferred from experience than when it is explicitly described (Huber et al., 2014).

The following two studies examine whether the attraction effect exists in decisions based on experience, in the context of gambles. We focus on gambles for two reasons: First, consumers face many risky choices that share similar attributes with gambles. For example, when consumers choose between investments or grocers, they need to trade off investment returns (or discount magnitude) with investment risks (or discount frequency), or when they choose between medical treatments, they need to trade off the positive (partial or full treatment) and negative outcomes (side effects) of each treatment with the likelihood of these events (Saporta-Sorozon, Danziger, \& Sloman, 2017). Second, much of the literature examining differences between description-based and experience-based choice examined choice between gambles (Barron \& Erev, 2003; Hertwig, 2012; Hertwig et al., 2004; Wulff, Mergenthaler Canseco, \& Hertwig, in press).

\section{STUDY 1}

Study 1 examined whether the attraction effect exists in experience-based choice between gambles. Traditional demonstrations of the attraction effect have compared the choice share of the two core options between two choice sets: one that included the two core options only and one that also included a third option-the decoy. However, other processes may confound comparing choice shares in two-option versus three-option choice sets. For example, choosing between three options is more cognitively taxing than

\footnotetext{
${ }^{1}$ It is important to note that by "experience-based choice," we refer to situations in which decision makers do not receive summary descriptions of outcome distributions but, rather, need to sample from these outcome distributions to learn about them. Following the sampling phase, decision makers make a single choice between the available distributions. Previous research by Trueblood and colleagues (Trueblood, 2012; Trueblood \& Pettibone, 2017; Trueblood et al., 2013) examined a series of choices in which the stimuli were rectangular shapes whose dimensions were not explicitly described but rather "experienced". In Trueblood's studies, "experience" refers to the perceptual nature of the stimuli. Participants in her studies made multiple choices, and the "experienced" shapes were not sampled from a single distribution that needed to be learned before choosing between these options but represented different stimuli.
}

choosing between two options (Neumann, Böckenholt, \& Sinha, 2016), and two-option versus three-option choice sets may have different ranges of presented options (Pettibone \& Wedell, 2000). To overcome potential confounds, we tested the attraction effect by comparing the choice share of the two core options in 2 three-option choice sets (Khan, Zhu, \& Kalra, 2011; Trueblood, 2012; Trueblood \& Pettibone, 2017; Trueblood et al., 2013). The gambles could vary on the outcome attribute, on the outcome probability attribute, or on both.

\section{Methods}

We recruited 350 US adults through Amazon Mechanical Turk $\left(46 \%\right.$ female; $\left.M_{\text {Age }}=35.4, S D_{\text {Age }}=11.1\right)$. Participants in each study were randomly assigned to one of eight conditions that varied in terms of the Dominant option (X vs. Y), Decoy attribute (outcome-based vs. probability-based decoy gamble), and Choice mode (experience vs. description).

Similar to Hertwig et al. (2004), participants were presented with three buttons on the computer screen, each representing an outcome distribution, and were asked to choose which button they would like to bet on once. In the description condition, the buttons were labeled with the outcomes and their probabilities. In the experience condition, the buttons were unlabeled, and participants had to sample outcomes to learn about them and their respective likelihoods. To avoid sampling error, we employed the matchedsampling paradigm (Ungemach, Chater, \& Stewart, 2009): Participants were instructed to sample each button 40 times, in any order. The relative frequency of each outcome matched its objective probability (such that no outcome remained unexperienced). Participants' instructed goal was to obtain as many points as possible. They were informed that the choices of five randomly selected participants would be rewarded with real money, and those participants would receive, in addition to the participation fee, 1 cent for each point won.

All four choice sets included the two core options, $\mathrm{X}$ and $\mathrm{Y}$, and a decoy option. Option $\mathrm{X}$ was the low-probability (high-risk) high-payoff option, offering a $12.5 \%$ chance of winning 36 points (and nothing otherwise). Option $\mathrm{Y}$ was the high-probability (low-risk) low-payoff option, offering a $75 \%$ chance of winning 6 points. Four different decoys were used: (1) an outcome-based decoy to option X, offering a $12.5 \%$ chance of winning 12 points, (2) an outcome-based decoy to option $\mathrm{Y}$, offering a $75 \%$ chance of winning 2 points, (3) a probability-based decoy to option X, offering a $2.5 \%$ chance of winning 36 points, and (4) a probabilitybased decoy to option $\mathrm{Y}$, offering a $15 \%$ chance of winning 6 points.

\section{Results}

Table 1 summarizes the choice share of each option, as well as the choice proportion of option $\mathrm{X}$ relative to the choice share of options X and Y (the two core options that appeared in all conditions), per condition. An attraction effect occurs if the choice proportion of option $\mathrm{X}$ (relative to the choice 
Table 1. Percentage of participants choosing each option in Study 1, by condition

\begin{tabular}{|c|c|c|c|c|c|c|c|}
\hline \multirow[b]{2}{*}{ Choice mode } & \multirow[b]{2}{*}{ Decoy attribute } & \multirow[b]{2}{*}{ Dominant option } & \multirow[b]{2}{*}{ Decoy gamble } & \multicolumn{3}{|c|}{ Choice share } & \multirow[b]{2}{*}{$\mathrm{X} /(\mathrm{X}+\mathrm{Y})$} \\
\hline & & & & $\begin{array}{c}\mathrm{X} \\
36(12.5 \%)^{\mathrm{a}}\end{array}$ & $\begin{array}{c}\mathrm{Y} \\
6(75 \%)\end{array}$ & Decoy & \\
\hline \multirow[t]{4}{*}{ Description } & \multirow[t]{2}{*}{ Outcome } & X & $12(12.5 \%)$ & $28(12)^{b}$ & $72(31)$ & $0(0)$ & 28 \\
\hline & & $\mathrm{Y}$ & $2(75 \%)$ & $5(2)$ & $90(38)$ & $5(2)$ & 5 \\
\hline & \multirow{2}{*}{ Prob. } & $X$ & $36(2.5 \%)$ & $31(13)$ & 69 (29) & $0(0)$ & 31 \\
\hline & & $\mathrm{Y}$ & $6(15 \%)$ & $5(2)$ & $95(39)$ & $0(0)$ & 5 \\
\hline \multirow[t]{4}{*}{ Experience } & \multirow[t]{2}{*}{ Outcome } & $X$ & $12(12.5 \%)$ & $54(22)$ & 41 (17) & $5(2)$ & 57 \\
\hline & & Y & $2(75 \%)$ & $36(18)$ & $62(31)$ & $2(1)$ & 37 \\
\hline & \multirow[t]{2}{*}{ Prob. } & $X$ & $36(2.5 \%)$ & $43(17)$ & $53(21)$ & $5(2)$ & 45 \\
\hline & & $\mathrm{Y}$ & $6(15 \%)$ & $46(23)$ & $50(25)$ & $4(2)$ & 48 \\
\hline
\end{tabular}

${ }^{\mathrm{a}} 12.5 \%$ chance of winning 36 points and nothing otherwise.

${ }^{\mathrm{b}}$ The number of participants choosing each option appears in the parentheses.

proportion of $\mathrm{X}$ and $\mathrm{Y}$, i.e., excluding the choice proportion of the decoy) is higher when it is the dominant option than when it is not (i.e., when gamble $\mathrm{Y}$ is the dominant option ${ }^{2}$ ).

Across Choice mode and Decoy attribute conditions, the relative choice proportion of option $\mathrm{X}$ was higher when it was the dominant option, relative to when $\mathrm{Y}$ was the dominant option, by $16 \%$ percentage points, suggesting an attraction effect exists.

Looking at each choice mode separately, in the description condition, an attraction effect seemed to exist in both Decoy attribute conditions, but in the experience condition, the attraction effect seemed to be limited to the outcome decoy. Specifically, in the description condition, the magnitude of the attraction effect was $23 \%$ in the outcome decoy condition (the choice share of gamble $\mathrm{X}$ was $28 \%$ when it was dominant gamble compared with $5 \%$ when $\mathrm{Y}$ was the dominant gamble) and $26 \%$ in the probability decoy condition (the choice share of gamble $\mathrm{X}$ was $31 \%$ when it was the dominant gamble compared with $5 \%$ when $\mathrm{Y}$ was the dominant gamble). In the experience condition, however, the magnitude of the attraction effect was $20 \%$ in the outcome decoy condition (the choice share of gamble $\mathrm{X}$ was $57 \%$ when it was the dominant gamble compared with $37 \%$ when $\mathrm{Y}$ was the dominant gamble), but no attraction effect was observed in the probability decoy condition (the choice share of gamble $\mathrm{X}$ was $45 \%$ when it was dominant gamble compared with $48 \%$ when $\mathrm{Y}$ was the dominant gamble).

We performed a logistic regression in which the likelihood of choosing option X (excluding decoy choices) was regressed on the Dominant option, Decoy attribute, Choice mode, and the interactions between them. The analysis indicated a significant Dominant option by Choice mode interaction, $\chi^{2}(1)=7.7 ; p=.006$. Further analyses revealed an attraction effect in the description condition but not in the experience condition: in the description condition, the average relative choice proportion of option $\mathrm{X}$ was higher when it was the dominant option, relative to when $\mathrm{Y}$ was the dominant option, by $26 \%$ percentage points (32\% vs.

\footnotetext{
${ }^{2}$ Note that by excluding choices of the decoy gamble, the choice share of gamble $\mathrm{X}$ is complementary to the choice share of gamble $\mathrm{Y}$.
}

$\left.6 \% ; \chi^{2}(1)=18.48 ; p=.0002\right)$. In the experience condition, it was higher by only $9 \%\left(52 \%\right.$ vs. $42 \% ; \chi^{2}(1)=1.21$; $p=.27)$. The analysis also revealed a main effect for the Dominant option, whereby the relative choice proportion of option $\mathrm{X}$ was higher when $\mathrm{X}$ was the dominant option than when $\mathrm{Y}$ was the dominant option $(41 \%$ vs. $25 \%$, $\left.\chi^{2}(1)=15.03 ; p=.0001\right)$, and a main effect for Choice mode, whereby the relative choice proportion of option $\mathrm{X}$ was higher in experience-based choice than in description-based choice $\left(46 \%\right.$ vs. $\left.19 \%, \chi^{2}(1)=28.07 ; p<.0001\right)$. All other effects were not significant.

Because the descriptive statistics indicate that the attraction effect emerges in all conditions but the experience-probability decoy condition, we further analyzed the three-way interaction between Dominant option, Decoy attribute, and Choice mode, although it was not statistically significant $\left(\chi^{2}(1)=1.93 ; p=.17\right)$. A series of four chi-squared analyses revealed a significant attraction effect in all but the experience-probability decoy condition. Specifically, the relative choice proportion of option $\mathrm{X}$ was higher when it was the dominant option than when $\mathrm{Y}$ was the dominant option in the description outcome decoy condition $\left(28 \%\right.$ vs. $\left.5 \%, \chi^{2}(1)=5.57 ; p=.01\right)$, in the description probability decoy condition $\left(31 \%\right.$ vs. $5 \%, \chi^{2}(1)=12.37$; $p=.0004)$, and in the experience outcome decoy condition (57\% vs. $37 \%$, a marginally significant effect: $\chi^{2}(1)=3.39$; $p=.066)$. In the experience-probability decoy condition, the relative choice proportion of option $\mathrm{X}$ was not significantly different when it was the dominant option compared with when $\mathrm{Y}$ was the dominant option $(45 \%$ vs. $48 \%$, $\left.\chi^{2}(1)=.09 ; p=.77\right)$.

\section{Discussion}

Consistent with previous research (Huber \& Puto, 1983; Huber et al., 1982; Simonson, 1989; Simonson \& Tversky, 1992), the results of Study 1 revealed an attraction effect in description-based choice. Adding to previous findings, the present results indicate that, in experience-based choice, an attraction effect occurs when the decoy is dominated on the outcome attribute but not when the decoy is dominated on the probability attribute. These results suggest that in both description-based and experience-based choice, decision 
makers may rely on dominance relationships to solve the difficult trade-off between risk and reward, but that using the dominance cue may be more limited in experience-based choice.

The present results raise the question why, in experiencebased choice, the attraction effect was found in the outcome decoy condition but not in the probability decoy condition. We examine two alternative reasons: First, in the probability decoy condition, participants may not have noticed the dominance relationship and therefore did not use it to guide choice. Indeed, in experience-based choice, when decisions makers sample gamble outcomes, probability-based decoys are more difficult to detect than outcome-based decoys (whereas in choices based on description, both types of decoys are equally easy to detect). With outcome-based decoys, one needs to experience the dominated outcome only once to notice the dominance relationship. For example, participants in this study needed to experience the outcome "12" and the outcome "36" only once to realize that former gamble is dominated by the latter gamble. However, with probability-based decoys, one needs to take at least a few samples and tally the number of samples in which each outcome occurred with each gamble in order to notice the dominance relationship. For example, participants in this study needed to experience the outcome " 36 " when sampling from the decoy gamble and when sampling from the dominant gamble, and to tally the frequency of the "36" outcome for each gamble to realize that one gamble is dominated by the other. The fact that the dominance relationship is more difficult to detect with probability decoys than with outcome decoys could explain why, in the experience condition, an attraction effect was found in the outcome decoy condition but not in the probability decoy condition. In contrast, in the description condition, where both outcomes and probabilities are explicitly described, the attraction effect is expected, and indeed occurred, with both types of decoys.

An alternative explanation for the results of Study 1 is that participants noticed the dominance relationship in all description-based and experience-based conditions but, for whatever reason, decided not to use dominance to solve the difficult trade-off between risk and reward in the experience-probability decoy condition. Study 2 attempts to test these two accounts by comparing the attraction effect in experience-based choice for participants who do and do not notice the dominance relationship. We focus on sets of gambles with experienced probability-based decoys because this is the only condition in which we found no indication for an attraction effect in Study 1.

\section{STUDY 2}

After sampling the distributions and making their choices, participants in Study 2 estimated the frequency with which each nonzero outcome was experienced, for each of the available gambles. We distinguish between participants whose estimates provide the basis for inferring dominance and participants whose estimates do not provide the basis for inferring dominance. ${ }^{3}$ We predicted that an attraction effect would be present only for those participants whose estimates provide the basis for inferring dominance.

\section{Methods}

We recruited 242 US adults through Amazon Mechanical Turk $\left(48 \%\right.$ female; $\left.M_{\text {Age }}=36.9, S D_{\text {Age }}=11.3\right)$. Participants were assigned to one of two choice conditions, each included a probability decoy: gamble $\mathrm{X}$ dominant condition-a choice set in which gamble $\mathrm{X}$ was the dominant option-and gamble Y dominant condition-a choice set in which gamble $\mathrm{Y}$ was the dominant option. Both choice sets included the same core gambles: gamble $\mathrm{X}$, which offered a $10 \%$ chance of winning 32 points (and nothing otherwise), and gamble $\mathrm{Y}$, which offered a $90 \%$ chance of winning 3 points. The probability decoy gamble in the $\mathrm{X}$ dominant condition offered a $5 \%$ chance of winning 32 points. The probability decoy gamble in the $\mathrm{Y}$ dominant condition offered a $45 \%$ chance of winning 3 points.

The procedure was similar to the experience condition of Study 1. Participants first sampled each unlabeled button 40 times, in any order, and then indicated which button they would like to bet on once. As in Study 1, we avoided sampling error by using the matched-sampling paradigm (Ungemach et al., 2009). Participants were also informed that the choices of five randomly selected participants would be rewarded with real money, and those participants would receive, in addition to the participation fee, 1 cent for each point won. After participants had terminated sampling and chosen their preferred button, for each button, they estimated in how many trials (of the 40 sampling trials per button) the nonzero outcome appeared.

\section{Results}

We classified participants according to whether their likelihood estimates provide the basis for inferring dominance (frequency judgments were converted to likelihood judgments by dividing each frequency judgment by 40 - the number of samples from each gamble). We first describe the classification rule and then analyze the results based on this rule.

\section{Classification rule}

When gamble $\mathrm{X}$ was dominant, only participants who estimated the probability of the decoy outcome as smaller than the probability of the dominant and the alternative options were assigned to the "basis for inferring dominance" group. When gamble Y was dominant, only participants who estimated the probability of the decoy outcome as smaller than the probability of the dominant option but larger than the probability of the alternative options were assigned to

\footnotetext{
${ }^{3}$ To avoid demand effects, we did not ask participants directly whether they had inferred the dominance relationship from the experienced outcomes.
} 
Table 2. Examples of how participants were classified according to whether their judgments provided a basis for inferring dominance in Study 2

\begin{tabular}{lccccc}
\hline Decoy gamble & Example & Gamble X 32, 10\% & Gamble Y 3, 90\% & Decoy & Basis for inferring dominance? \\
\hline $32,5 \%$ (X dom. cond.) & 1 & $20 \%$ & $80 \%$ & $7 \%$ & Yes \\
$3,45 \%$ (Y dom. cond.) & 2 & $7 \%$ & $80 \%$ & $7 \%$ & No \\
& 4 & $20 \%$ & $80 \%$ & $70 \%$ & Yes \\
\end{tabular}

${ }^{\mathrm{a}} 10 \%$ chance of winning 32 points and nothing otherwise.

the "basis for inferring dominance" group. Table 2 provides several applications of the classification rule. To illustrate, consider Example 1 in Table 2, of a participant who estimated the probability of the dominant option (gamble $\mathrm{X}$ ) as $20 \%$, the probability of the decoy gamble (of X) as $7 \%$, and the probability of the alternative option (gamble Y) as $80 \%$. Although these estimates were inaccurate, they still reflect a dominance relationship because the dominant option is more probable than the decoy (and the outcome is the same). This participant was thus classified as someone whose estimates provide a basis for inferring dominance. By contrast, consider the second example in Table 2, of a person who estimated the probability of the dominant option (gamble X) and the probability of the decoy option (of X) as $7 \%$, and the probability of the alternative option (gamble Y) as $20 \%$. These estimates do not provide a basis for inferring dominance because the judged probability of the nonzero outcome (which was 32 in both cases) was $7 \%$ in both cases. This participant was thus classified as someone whose estimates did not provide a basis for inferring dominance.

Based on this classification rule, the estimates of $64 \%$ of the participants were classified as serving the basis for inferring dominance $(51 \%$ of the participants in the gamble $\mathrm{X}$ dominant condition and $78 \%$ of the participants in the gamble Y dominant condition).

\section{Data analysis}

Table 3 summarizes the choice share of each option, as well as the choice share of option $\mathrm{X}$ relative to the choice share of the core options, $\mathrm{X}$ and $\mathrm{Y}$, per condition, and separately for participants whose estimates served or did not serve the basis for inferring dominance. As in Study 1, an attraction effect occurs if the relative proportion of $\mathrm{X}$ choices is higher when it is the dominating option than when $\mathrm{Y}$ is the dominating option.

Table 3. Percentage of participants choosing each option in Study 2 , by condition

\begin{tabular}{lccccc}
\hline $\begin{array}{l}\text { Basis for } \\
\text { inferring } \\
\text { dominance? }\end{array}$ & $\begin{array}{c}\text { Dominant } \\
\text { gamble }\end{array}$ & \multicolumn{3}{c}{ Choice share } & X/ \\
\cline { 3 - 5 } & & $\mathrm{X}$ & $\mathrm{Y}$ & Decoy & \\
\hline Yes & $\mathrm{X}$ & $50(31)$ & $48(31)$ & $2(1)$ & 51 \\
& $\mathrm{Y}$ & $38(35)$ & $62(58)$ & $0(0)$ & 38 \\
No & $\mathrm{X}$ & $20(12)$ & $58(35)$ & $22(13)$ & 26 \\
& $\mathrm{Y}$ & $41(11)$ & $37(10)$ & $22(6)$ & 53 \\
\hline
\end{tabular}

Note: The number of participants choosing each option appears in the parentheses.
As Table 3 demonstrates, the existence of the attraction effect was contingent on whether participants' estimates rendered possible the inference of dominance: When they did, the relative choice proportion of option $X$ was higher when it was the dominant option, relative to when $\mathrm{Y}$ was the dominant option, by $13 \%$ ( $51 \%$ vs. $38 \%$ ), suggesting an attraction effect. In contrast, when participants' estimates did not render possible the inference of dominance, the relative choice proportion of option $\mathrm{X}$ was lower when it was the dominant option, relative to when $\mathrm{Y}$ was the dominant option, by $27 \%$ ( $26 \%$ vs. $53 \%$ ), a pattern opposite to an attraction effect, often referred to as a "repulsion" effect. ${ }^{4}$

We performed a logistic regression in which the likelihood of choosing option $\mathrm{X}$ (excluding decoy choices) was regressed on the Dominant option and on whether the participant's judgments served as a basis for inferring dominance or not, and the interactions between them. The analysis indicated a significant interaction effect, $\chi^{2}(1)=7 ; p=.008$. Further analyses revealed an attraction effect among participants whose estimates suggested dominance (51\% vs. $38 \%$; $\left.\chi^{2}(1)=2.62 ; p=.1\right)$ but a repulsion effect among participants whose judgments did not suggest dominance (26\% vs. $53 \%$; $\left.\chi^{2}(1)=4.67 ; p=.03\right)$. The main effects of the Dominant option $\left(\chi^{2}(1)=.16 ; p=.33\right)$ and on whether the participant's judgments served as a basis for inferring dominance or not $\left(\chi^{2}(1)=.13 ; p=.44\right)$ were not significant.

\section{Discussion}

The results of Study 2 demonstrated that consumers whose estimates could have led them to infer dominance were more likely to choose the dominant option, resulting in an attraction effect, relative to consumers whose estimates could not have led them to infer dominance. These findings suggest that the failure to find an attraction effect in the probability decoy of the experience condition in Study 1 results from the greater difficulty to recognize the dominance relationship in experience-based choice than in description-based choice, in particular when the decoy is dominated along the probability attribute. As the present results show, people who have likely detected the dominance relationship were more likely to use it to solve the difficult trade-off between risk and reward in experience-based choice.

\footnotetext{
${ }^{4} \mathrm{~A}$ repulsion effect occurs when adding an inferior option (a decoy) to a twooption choice set characterized by a difficult trade-off between two attributes increases the choice share of the alternative option (and not the option that dominates the decoy; Frederick et al., 2014; Simonson, 2014).
} 
As mentioned before, to avoid demand characteristics, we did not explicitly ask participants whether they had noted the dominance relationship. Rather, we examined whether their estimate served as a basis for inferring dominance, which constitutes a strong test for our findings. Participants whose estimates did not suggest dominance probably did not infer that a dominance relationship between the gambles existed. However, participants whose estimates suggested dominance may or may not have actually recognized it. To actually notice the dominance relationship, one must not only estimate the probability of the outcome of each gamble but also compare these quantities and, in addition, realize the probability of the decoy gamble is lower than that of the dominant gamble. Therefore, some participants classified as having a "basis for inferring dominance" might not have been aware of this relationship. Because these participants are unlikely to use the dominance cue for choice, their inclusion in the "basis for inferring dominance" group probably weakened the attraction effect. The fact that we still found an attraction effect is a strong support for its existence.

\section{GENERAL DISCUSSION}

We examined whether the attraction effect extends from description-based to experience-based choice. The results of Study 1 suggest that the attraction effect extends to experience-based choice when the decoy is dominated along the outcome attribute but not when it is dominated along the probability attribute. The results of Study 2 qualify this finding and demonstrate that, when the decoy is dominated along the probability attribute in experience-based choice, those participants whose estimates would enable them to infer a dominance relationship were more likely to choose the dominant option than participants who estimates did not suggest such a relationship. The choices of the former were more likely to give rise to an attraction effect.

The present paper makes several theoretical contributions. First, it contributes to research on consumer choice and the attraction effect by demonstrating that the attraction effect may occur when consumers base their choice on experience with product attributes rather than on descriptions thereof. Second, it explains that the attraction effect is less likely to occur in experience-based choice when the decoy is dominated along the probability attribute, because recognizing the dominance relation is a necessary condition for the attraction effect, and recognizing this relationship is more difficult when it must be inferred from experience than when it is explicitly described or when the decoy is dominated along the outcome attribute (Huber et al., 2014). Our results also suggest that if there is perception noise on the outcome attribute, rendering it difficult to discriminate between options' outcomes (e.g., when one experiences traffic volumes at different roads), results similar to ours would be observed for the outcome attribute (Shafir, Reich, Tsur, Erev, \& Lotem, 2008).

Third, this research contributes to the literature on experience-based choice by demonstrating that people may use a dominance cue to choose between experience-based options. Specifically, tested primarily with two-option choice sets, ${ }^{5}$ previous research finds that when people choose based on their experiences, they typically choose the option that provides a high probability of a relatively small payoff over an option that provides a low probability of a higher payoff (Barron \& Erev, 2003; Danziger, Hadar, \& Morwitz, 2014; Hertwig, 2012; Hertwig et al., 2004). Several choice strategies have been offered to explain this choice pattern: probability matching (people choose the more frequently rewarding option more often because it more often offers a higher payoff; Erev \& Barron, 2005; Estes, 1961), predicting future outcomes based on previously experienced ones (Gonzalez \& Dutt, 2011), or mental accounting (Danziger et al., 2014; Payne, 2005; Thaler, 1985). By providing a richer choice environment characterized by asymmetrically dominant relations between choice options, our studies show that people may also use dominance to make choices based on experience.

It is important to note that the attraction effect is less likely to occur in experience-based choice in real life than in our studies. Drawing on Fox and Hadar (2006; Hadar \& Fox, 2009), consumers may not notice the dominance relation in experience-based choice for two reasons: First, because of limited attention, information, memory, and so on, consumers' judgments often may not accurately reflect what they experienced. Indeed, in Study 2, although all of the participants experienced a dominance relationship, the estimates of only $64 \%$ of the participants suggested dominance. Second, consumers' experiences frequently do not match the real event distributions because of small sample size and sampling error. For example, if an investment is profitable $10 \%$ of the time (assuming a large sample size), a consumer monitoring for only 6 months may fail to experience any profits. In the present studies, we avoided sampling error by using the matched-sampling paradigm. Participants were required to sample each button 40 times, and their samples matched the actual outcome distributions. For example, when sampling the button associated with option $\mathrm{X}$ in Study $1-$ a $12.5 \%$ probability of winning 36 and nothing otherwise-participants experienced the outcome 36 five times and the outcome zero 35 times, out of 40 . However, when full descriptions of choice options are not available, small samples, sampling error, and sequence effects (e.g., recency) are likely to be prevalent. The opportunity for consumers to become aware of the dominance relationship is even less likely in real life than in our experiment, because it depends not only on estimation bias but also on sampling error.

Our results also have practical implications. These suggest that the attraction effect is more likely to occur with products/services for which precise attribute values are typically described (e.g., product price and length of warranty). In situations in which practitioners want to utilize the attraction effect to guide choice and in which descriptive information is not usually available (e.g., the likelihood and

\footnotetext{
${ }^{5}$ Studies examining multiple-option settings did not investigate the attraction effect (Frey, Mata, \& Hertwig, 2015; Hills, Noguchi, \& Gibbert, 2013).
} 
magnitude of product discounts; Danziger et al., 2014), they could increase the transparency of the dominance relationship by providing descriptive information (e.g., summary statistics on the performance of investment funds over a long period of time) or by encouraging consumers to experience the product/service multiple times (e.g., offering potential customers the opportunity to manage a simulated investment portfolio before actually choosing one). Practitioners could also try to determine how much experience consumers typically collect before choosing a product or service. Based on the amount of consumers' pre-purchase experience, one could estimate the likelihood that consumers will have experienced a dominance relationship.

\section{ACKNOWLEDGEMENTS}

We thank Shane Frederick and three anonymous reviewers for their helpful comments and suggestions. This research was supported by the Israel Science Foundation grant 775/14 to Shai Danziger and Liat Hadar.

\section{REFERENCES}

Amir, O., \& Levav, J. (2008). Choice construction versus preference construction: The instability of preferences learned in context. Journal of Marketing Research, 45, 145-158.

Barron, G., \& Erev, I. (2003). Small feedback-based decisions and their limited correspondence to description-based decisions. Journal of Behavioral Decision Making, 16, 215-233.

Danziger, S., Hadar, L., \& Morwitz, V. (2014). Retailer pricing strategy and consumer choice under price uncertainty. Journal of Consumer Research, 41, 761-774.

Erev, I., \& Barron, G. (2005). On adaptation, maximization, and reinforcement learning among cognitive strategies. Psychological Review, 12(4), 912-931.

Estes, W. K. (1961). A descriptive approach to the dynamics of choice behavior. Behavioral Science, 6(3), 177-184.

Evangelidis, I., \& Levav, J. (2013). Prominence versus dominance: How relationships between alternatives drive decision strategy and choice. Journal of Marketing Research, 50(6), 753-766.

Fox, C. R., \& Hadar, L. (2006). Decisions from experience $=$ Sampling error + prospect theory: Reconsidering Hertwig, Barron, Weber \& Erev (2004). Judgment and Decision making, 1(2), $159-161$.

Frederick, S., Lee, L., \& Baskin, E. (2014). The limits of attraction. Journal of Marketing Research, 31, 487-507.

Frey, R., Mata, R., \& Hertwig, R. (2015). The role of cognitive abilities in decisions from experience: Age differences emerge as a function of choice set size. Cognition, 142, 60-80.

Gonzalez, C., \& Dutt, V. (2011). Instance-based learning: Integrating sampling and repeated decisions from experience. Psychological Review, 118(4), 523-551.

Hadar, L., \& Fox, C. R. (2009). Information asymmetry in decision from description versus decision from experience. Judgment and Decision making, 4(4), 317-325.

Herne, K. (1997). Decoy alternatives in policy choices: Asymmetric domination and compromise effects. European Journal of Political Economy, 13(3), 575-589.

Hertwig, R. (2012). The psychology and rationality of decisions from experience. Synthese, 187, 269-292.

Hertwig, R., Barron, G., Weber, E. U., \& Erev, I. (2004). Decisions from experience and the effect of rare events in risky choice. Psychological Science, 15(8), 534-539.
Hills, T. T., Noguchi, T., \& Gibbert, M. (2013). Information overload or search-amplified risk? Set size and order effects on decisions from experience. Psychonomic Bulletin \& Review, 20(5), 1023-1031.

Huber, J., Payne, J. W., \& Puto, C. (1982). Adding asymmetrically dominated alternatives: Violations of the regularity and similarity hypothesis. Journal of Consumer Research, 9(1), 90-98.

Huber, J., Payne, J. W., \& Puto, C. (2014). Let's be honest about the attraction effect. Journal of Marketing Research, 51(4), $520-525$.

Huber, J., \& Puto, C. (1983). Market boundaries and product choice: Illustrating attraction and substitution effects. Journal of Consumer Research, 10, 31-41.

Kelman, M., Rottenstreich, Y., \& Tversky, A. (1996). Contextdependence in legal decision making. The Journal of Legal Studies, 25(2), 287-318.

Khan, U., Zhu, M., \& Kalra, A. (2011). When trade-offs matter: The effect of choice construal on context effects. Journal of Marketing Research, 48, 62-71.

Levav, J., Kivetz, R., \& Cho, C. K. (2010). Motivational compatibility and choice conflict. Journal of Consumer Research, 31(3), 429-442.

Luce, R. D. (1977). The choice axiom after twenty years. Journal of Mathematical Psychology, 15(3), 215-233.

Maylor, E., \& Roberts, M. A. J. (2007). Similarity and attraction effects in episodic memory judgments. Cognition, 105(3), 715-723.

Moran, S., \& Meyer, J. (2006). Using context effects to increase a leader's advantage: What set of alternatives should be included in the comparison set? International Journal of Research in Marketing, 23, 141-154.

Neumann, N., Böckenholt, U., \& Sinha, A. (2016). A meta-analysis of extremeness aversion. Journal of Consumer Psychology, $26(2,193-212$.

Payne, J. (2005). It is whether you win or lose: The importance of the overall probabilities of winning or losing in risky choice. Journal of Risk and Uncertainty, 30(1), 5-19.

Pettibone, J. C., \& Wedell, D. H. (2000). Examining models of non-dominated decoy effects across judgment and choice. Organizational Behavior and Human Decision Processes, 81(2), 300-328.

Saporta-Sorozon, K., Danziger, S., \& Sloman, S. (2017). Causal reasoning drives preference between drugs that treat a focal symptom vs. multiple symptoms. Journal of Behavioral Decision Making. https://doi.org/10.1002/bdm.1999.

Shafir, S., Reich, T., Tsur, E., Erev, I., \& Lotem, A. (2008). Perceptual accuracy and conflicting effects of certainty on risk-taking behaviour. Nature, 453(7197), 917.

Simonson, I. (1989). Choice based on reasons: The case of attraction and compromise effects. Journal of Consumer Research, 16(2), 158-174.

Simonson, I. (2014). Vices and virtues of misguided replications: The case of asymmetric dominance. Journal of Marketing Research, 51(August), 514-519.

Simonson, I., \& Nowlis, S. M. (2000). The role of explanations and need for uniqueness in consumer decision making: Unconventional choices based on reasons. Journal of Consumer Research, 27, 49-68.

Simonson, I., \& Tversky, A. (1992). Choice in context: Tradeoff contrast and extremeness aversion. Journal of Marketing Research, 29, 281-295.

Slaughter, J. E., Sinar, E. F., \& Highhouse, S. (1999). Decoy effects and attribute-level inferences. Journal of Applied Psychology, 84(5), 823-828.

Thaler, R. H. (1985). Mental accounting and consumer choice. Marketing Science, 4, 199-214.

Trueblood, J. S. (2012). Multi-alternative context effects obtained using an inference task. Psychonomic Bulletin \& Review, 19(5), 962-968. https://doi.org/10.3758/s13423-012-0288-9. 
Trueblood, J. S., Brown, S. D., Heathcote, A., \& Busemeyer, J. R. (2013). Not just for consumers: Context effects are fundamental to decision making. Psychological Science, 24(6), 901-908.

Trueblood, J. S., \& Pettibone, J. C. (2017). The phantom decoy effect in perceptual decision-making. Journal of Behavioral Decision Making, 30(2), 157-167.
Ungemach, C., Chater, N., \& Stewart, N. (2009). Are probabilities overweighted or underweighted when rare outcomes are experienced (rarely)? Psychological Science, 20(4), 473-479.

Wulff, D., Mergenthaler Canseco, M., \& Hertwig, R. (in press). A meta-analytic review of two modes of learning and the description-experience gap. Psychological Bulletin. 